\title{
Correction to: Physiological and histopathological assessments of the susceptibility of different tomato (Solanum lycopersicum) cultivars to early blight disease
}

\author{
Nashwa M. A. Sallam (D) Heba-Alla S. AbdElfatah • \\ Mona F. A. Dawood • Elhagag Ahmed Hassan • \\ Mohamed S. Mohamed • Hadeel M. M. Khalil Bagy \\ Published online: 21 April 2021 \\ (C) Koninklijke Nederlandse Planteziektenkundige Vereniging 2021
}

\section{Correction to: Eur J Plant Pathol}

https://doi.org/10.1007/s10658-021-02263-2

An incorrect version of fig. 8 was published in the original article and this erratum reflects the correct version.

The online version of the original article can be found at https://doi.org/10.1007/s10658-021-02263-2

N. M. A. Sallam $(\bowtie) \cdot$ H.-A. S. AbdElfatah •

M. S. Mohamed • H. M. M. Khalil Bagy

Faculty of Agriculture, Plant Pathology Department, Assiut

University, Assiut 71526, Egypt

e-mail: nashwasallam@aun.edu.eg

M. F. A. Dawood · E. A. Hassan

Faculty of Science, Botany and Microbiology Department, Assiut

University, Assiut, Egypt 
Fig. 8 Scanning electron micrographs showing healthy tomato CV1 (a), healthy tomato susceptible CV5 (b) compared with infected tomato $\mathrm{CV} 1$ (A. solani and C. lunata respectively) (c \& d) that showing no colonization of fungal hyphae. Note the infected tomato susceptible cultivar (e \& f) showing colonization of fungal mycelia and conidia formation

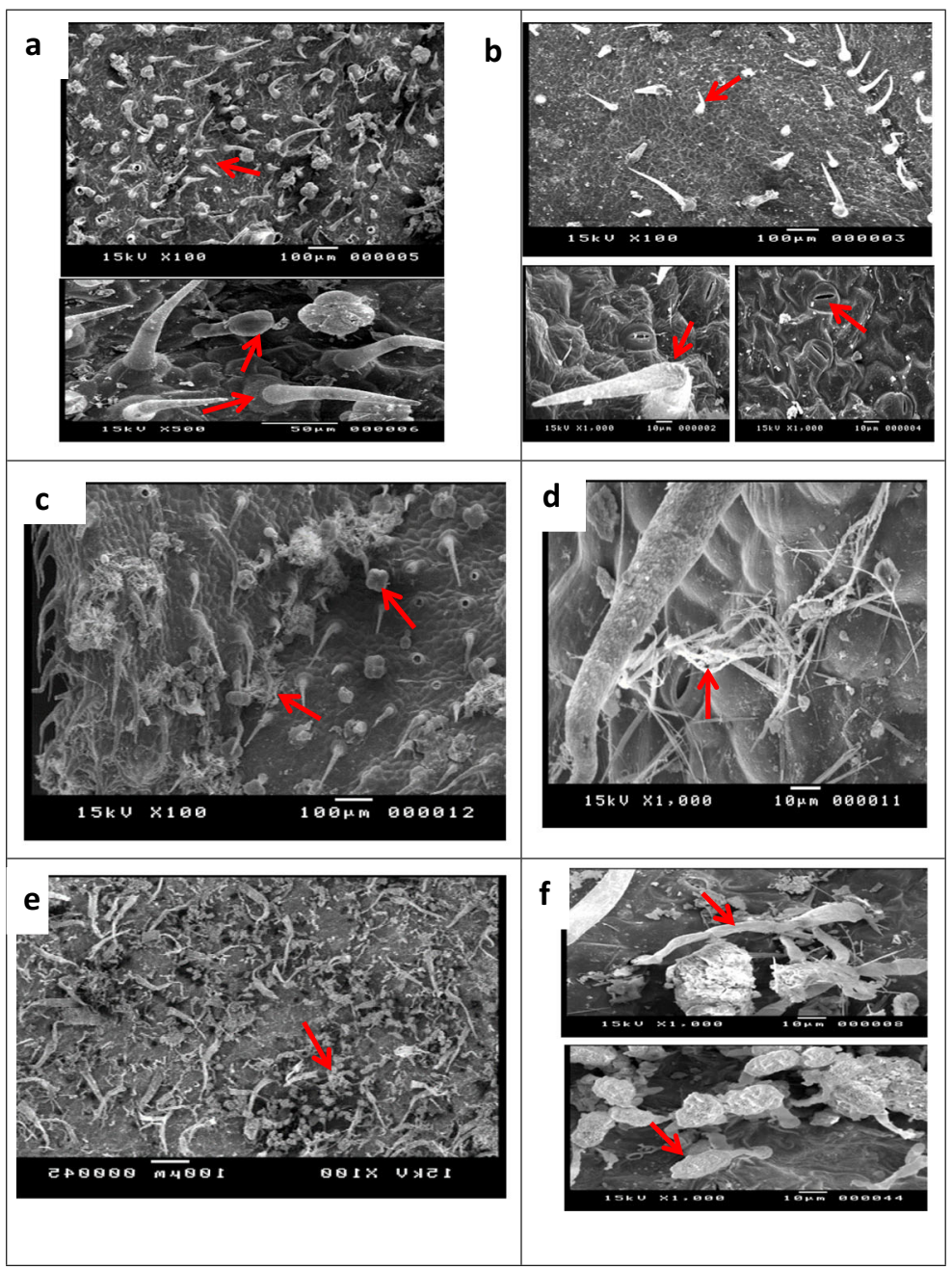

